\title{
Fostering wellbeing among workers who support refugees and asylum seekers in the Australian context
}

Dr Miriam Posselt ${ }^{1 / 3}$, Dr Amy Baker ${ }^{1 / 2}$, Dr Carolyn Deans ${ }^{3 / 4}$, Professor Nicholas Procter ${ }^{1}$.

1. Mental Health and Suicide Prevention Research Group, Division of Health Sciences, University of South Australia, Adelaide, Australia.

2. School of Health Sciences, University of South Australia, Adelaide, Australia.

3. College of Health \& Biomedicine, Victoria University, Melbourne, Australia.

4. Phoenix Australia: Centre for Post Traumatic Mental Health, University of Melbourne, Melbourne, Australia.

\section{Corresponding author:}

Dr Miriam Posselt, Mental Health and Suicide Prevention Research Group, Division of Health Sciences, University of South Australia.

GPO Box 2471, Adelaide, Australia, 5001.

Phone: +61883021608 .

Email: Miriam.posselt@unisa.edu.au

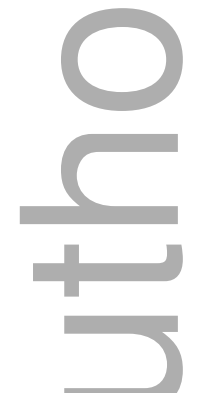

\section{Acknowledgements}

We would like to acknowledge the following organisations that supported and promoted this research: ASeTTS, STTARS, Foundation House, Companion House, QPASTT, Melaleuca Refugee Centre, STARTTS, and OSSTT.

This is the author manuscript accepted for publication and has undergone full peer review but has not been through the copyediting, typesetting, pagination and proofreading process, which may lead to differences between this version and the Version of Record. Please cite this article as doi: $\underline{10.1111 / \text { HSC.12991 }}$

This article is protected by copyright. All rights reserved 


\section{Conflict of interest}

The authors have no conflict of interest to declare.

\section{Funding}

No funding was received to conduct this research.
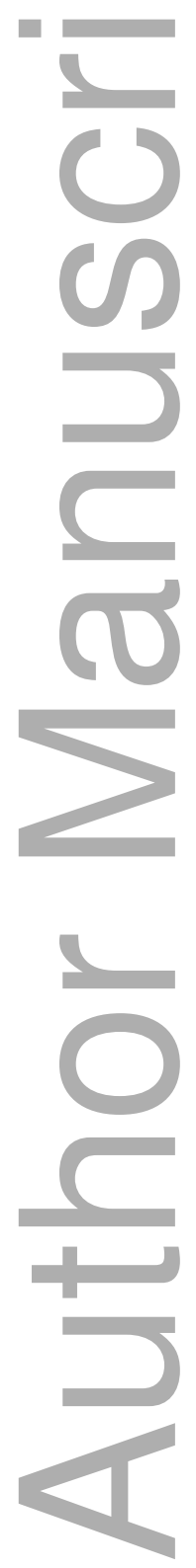

This article is protected by copyright. All rights reserved 


\title{
Fostering mental health and wellbeing among workers who support refugees and asylum seekers in the Australian context
}

\begin{abstract}
Therapists and counsellors who provide trauma-focussed therapy and support to refugees and asylum seekers are often exposed to distressing and confronting stories of war, violence, torture, loss and grief, and other atrocities. In addition to this, working within an immigration and detention context has been reported to further contribute to experiences of burnout, vicarious trauma, and other adverse consequences of working with traumatised populations. There is a scarcity of research seeking to understand how therapists address these difficulties and maintain wellbeing to help them continue in this field of work. This mixed-methods research aimed to identify and explore factors associated with mental health and wellbeing among workers, with a particular focus on the role of clinical supervision. Participants were staff $(n=50)$ who identified as providing therapeutic support to refugees and asylum seekers either in Australia or in Australian-run detention facilities. Participants took part in an anonymous online survey which focussed on the psychological impact of their work, professional quality of life, and clinical supervision and incorporated free-text items. Thematic analysis of free-text data revealed four themes related to maintaining wellbeing at work including relationships and support seeking; physical and contemplative practices; professional growth; and balance and boundaries. Results from the quantitative analyses revealed several variables related to supervision that were important for wellbeing. In particular, the findings suggest that rapport and overall alliance with one's clinical supervisor are protective of secondary traumatic stress and depression, respectively. Important aspects of supervision were also explored in greater depth through qualitative and quantitative inquiry, increasing our understanding of the mechanisms underlying the relationship between clinical supervision and mental health and wellbeing for this group.
\end{abstract}

Key words: refugees, asylum seekers, staff wellbeing, supervision, self-care, burnout

\section{What is known about this topic}

- Workers who support refugees and asylum seekers are often reported to experience adverse mental health outcomes as a result of their jobs. 
- Research has highlighted that self-care practices and supervision are important resources in promoting mental health and wellbeing for workers, however, little research has comprehensively explored this.

\section{What this paper adds}

- This paper explores resources that foster mental health and wellbeing among therapists who support refugees and asylum seekers. Wellbeing was found to be related to relationships and support seeking; physical and contemplative practices; professional growth; balance and boundaries.

- Supervision which incorporates both educational and emotionally supportive aspects, in which a strong rapport and alliance exists, appeared to be critical.

\section{( ) \\ Introduction}

Workers who provide therapeutic support to refugees and asylum seekers will, by the nature of their work, be exposed to narratives of torture, trauma, loss and distress. The negative mental health consequences of prolonged indefinite immigration detention, refugee status determination and insecure visa status on asylum seekers and refugees are also well documented (Newnham, Pearman, Olinga-Shannon, \& Nickerson, 2019; Robjant, Robbins, \& Senior, 2009; Silove, Steel, \& Watters, 2000). Research has suggested that these processes also have a significant impact on the mental health and wellbeing of individuals who support them (Posselt, Deans, Baker \& Procter, 2019; Puvimanasinghe, Denson, Augoustinos, \& Somasundaram, 2015; Robinson, 2014).

Vicarious trauma, compassion fatigue, burnout, and secondary traumatic stress (STS) are some of the documented adverse consequences of working in this field. High levels of burnout (feelings of helplessness, hopelessness, overwhelmed by one's work, and physical and emotional exhaustion; Stamm, 2010) and STS (resulting from secondary exposure to people who have experienced trauma and involving experiences of fear, sleep difficulties, intrusive images, or avoiding reminders of the client's traumatic experiences; Stamm, 2010) have been reported among therapists working with refugee populations (Birck, 2002; Deighton, Gurris, \& Traue, 2007; Guhan \& Liebling-Kalifani, 2011). However, positive impacts have also been reported such as finding levels of compassion satisfaction (finding meaning and purpose in one's work; Stamm, 2010), within the high or normal range (Birck, 2002; Guhan \& Liebling-Kalifani, 2011; Kjellenberg, Nilsson, Daukantaité \& Cardeña, 2014; 
Posselt et al., 2019). A number of qualitative studies have reported positive consequences such as enriched lives, meaning making and vicarious posttraumatic growth (Apostolidou, 2016; Barrington and Shakespeare-Finch, 2013; Barrington \& Shakespeare-Finch, 2014; Posselt et al., 2019; Puvimanasinghe et al., 2015).

Years spent working in the field (Birck, 2002; Kjellenberg et al., 2014), time spent working with clients during the week, number of clients seen in a week (Birck, 2002; Deighton et al., 2007), and personal trauma history (Deighton et al., 2007) are specific job demands that are reported to be associated with greater levels of burnout, compassion fatigue, and STS. These demands, however, have not been found to be consistently related to mental health and wellbeing. Many risk factors are likely to be idiosyncratic, may be inherent to the job and may not be amenable to reduction or removal.

\section{Theoretical framework}

The protective role of job resources in minimising risk of adverse outcomes has been researched in relation to other trauma exposed occupations such as firefighters (Tuckey \& Hayward, 2011). Little research has been conducted looking at protective factors or resources which could be implemented to buffer against potential negative impacts for trauma workers who support refugees and asylum seekers. The Job Demands-Resources (JD-R) model posits that burnout and poor psychological health can result from an imbalance between job demands and resources and that having adequate job resources may buffer against the influence of job demands (Bakker, Demerouti \& Euwema, 2005). The JD-R model suggests that each occupation may have its own specific risk factors for stress, and that resources that play a protective role may depend on specific job characteristics. The idea behind this model is that worker mental health and wellbeing can be maintained through providing adequate resources, even when demands cannot be removed or reduced (Bakker et al., 2005).

\section{Potential resources}

Both Barrington and Shakespeare-Finch (2013) and Robinson (2014) found that participants reported involvement in advocacy, campaigns and political activism, driven by feeling frustrated and powerless with respect to the immigration process. It remains unclear whether this involvement could serve a protective purpose and be a potential resource in this line of work.

Qualitative evidence concerning working with refugee populations has emphasised that supervision is an important resource for staff wellbeing and staff retention (Apostolidou \& Schweitzer, 2017; Barrington \& Shakespeare-Finch, 2013; Guhan \& Liebling-Kalifani, 2011; Puvimanasinghe et al., 2015; Robinson, 2013). Puvimanasinghe et al. (2015) also noted 
that continuous supervision is critical in addressing vicarious trauma and other harmful effects of working with this population. Guhan and Liebling-Kalifani (2011) also identified that supervision was important, however, suggested that future research focus on the precise mechanisms that serve to buffer against the negative impacts of working with this population in order to assist in developing supervision manuals for refugee support services.

Despite the consensus that supervision is crucial, there is little quantitative research to support this and no research has comprehensively examined the different aspects of supervision that may be important for the wellbeing of workers supporting refugees and asylum seekers.

Further, no study has used mixed-methods to comprehensively examine resources that foster wellbeing among Australian workers who support refugees and asylum seekers.

This study aimed to a) explore the perspectives of workers regarding what fosters mental health and wellbeing in their role (job resources) b) explore factors that were associated with mental health and wellbeing among these workers (demands and resources), particularly political activism/ advocacy and supervision-related factors, and c) explore what specific aspects of supervision (a particular resource), if any, were important in maintaining worker mental health and wellbeing.

This research conceptualised mental health and wellbeing as comprising two aspects: psychological health (defined as levels of depression, anxiety, stress), and professional quality of life (levels of compassion satisfaction, STS and burnout). At times, the term wellbeing is used to summarise these concepts.

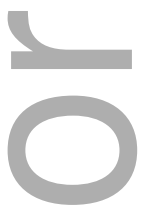

\section{Participants and research setting}

The findings presented are from a nation-wide survey in Australia of people who work therapeutically with refugee and asylum seeker survivors of torture and trauma. Participants were eligible if they were aged 18 years and over and worked in Australia or in Australianrun immigration detention facilities. The research received approval from the University of South Australia Human Research Ethics Committee.

Participants were recruited by contacting agencies across Australia that form the Forum of Australian Services for Survivors of Torture and Trauma (FASSTT), a network of eight specialist rehabilitation agencies that provide psychological services to individuals from refugee and asylum seeker backgrounds. An agency affiliated with FASSTT which provides 
torture and trauma counselling services to asylum seekers and refugees in immigration detention environments in Nauru and Papua New Guinea was also invited to participate. Recruitment emails containing the study information and survey link were distributed to eligible staff members across consenting agencies, via a member of management. A total of 50 participants took part in the survey with $82 \%(n=41)$ completing the entire survey. It was estimated that the survey was sent to approximately 220 eligible staff, therefore, our estimated response rate was approximately $23 \%$.

Participants were aged 26-68 years $(M=41, S D=11.84)$ and were male $(22 \%, \mathrm{n}=$ $11)$, female $(72 \%, \mathrm{n}=36)$ or preferred to not disclose gender $(6 \%)$. Participants reported a wide range of experience working in the trauma field, from less than one year to 20 years $(\mathrm{M}$ $=6.73, \mathrm{SD}=5.08$ ) and a similar range of time working with refugees or asylum seekers, from less than one year to 20 years $(\mathrm{M}=5.62, \mathrm{SD}=5.10)$. Additional demographic and sample characteristic information is displayed in Table 1.

[INSERT TABLE 1 HERE]

\section{Survey}

This study consisted of participation in an online-survey which was conducted using Qualtrics Online Survey Software (Qualtrics, 2014), promoting confidentiality and anonymity of participants and enabling data collection from across Australia. The onlinesurvey consisted of demographic questions, three scales, and open-ended free-text questions. As psychological health and professional quality of life were outcomes of interest, the Depression, Anxiety and Stress Scale (DASS-21) (Lovibond \& Lovibond, 1995) and the Professional Quality of Life Scale- Version 5 (ProQOL-V, 2009) (Stamm, 2010) were used.

The DASS-21 is a 21-item measure of depression, anxiety and stress with good psychometric properties and has been validated for use among both clinical and non-clinical adult samples (Brown, Chorpita, Korotitsch, \& Barlow, 1997; Henry \& Crawford, 2005; Lovibond \& Lovibond, 1995). Participants rate on a scale of 0 ("not at all/ never") to 3 ("very much, or most of the time/ almost always") how much each statement applied to them in the past week.

The ProQOL-Version 5 is a 30-item measure of compassion satisfaction, burnout and STS and has demonstrated excellent reliability and construct validity (Stamm, 2010).

Participants rate on a scale of 1 (never) to 5 (very often) the frequency that they experienced each symptom over the past month. 
To measure aspects of clinical supervision, the Supervisory Working Alliance Inventory (SWAI)-Supervisee Version (Efstation, Patton \& Kardash, 1990) and additional supervision related questions were used. The SWAI-Supervisee Version consists of 19 items and aims to measure a therapist's perception of their relationship with their clinical supervisor. The SWAI has two subscales: Rapport and Client Focus. Participants are asked to indicate the frequency from 1 (almost never) to 7 (almost always) with which they perceive supervisors to demonstrate certain characteristics and behaviours. Research has demonstrated the SWAI has good psychometric properties and its original factor structure has been replicated with diverse samples (Efstation, Patton, \& Kardash, 1990; Patton, 1992).

Additionally, a series of questions relating to aspects of supervision not addressed by the SWAI were included in the survey and preceded the SWAI. This included whether they received supervision, whether they provided supervision to others, and supervision frequency. According to Baglow (2009) and drawing on the work of Kadushin (1976) and Shulman (1982), the four key functions of supervision are administrative or managerial (time management, caseloads, paper work); educational and professional development; emotional or psychological support; and mediation (between worker and organisation/external individuals). Four questions were included in the survey that corresponded with Baglow's (2009) aspects of supervision. Participants were asked to rate the frequency in which each of these four aspects were addressed in their current supervision from 1 (never) to 5 (very often).

The survey also comprised open-ended questions to collect the qualitative data. Participants were encouraged to write freely and describe the impacts of their work (published elsewhere) and what it takes to maintain wellbeing in their role.

The survey took approximately 10-20 minutes to complete. Data were collected between June 2016 and March 2017.

\section{Ethical considerations}

At the time this research was conducted, disclosure of protected information regarding work with asylum seekers or in immigration detention centres was considered a breach of the Australian Border Force Act 2015 with a potential penalty of two years imprisonment (Department of Immigration and Border Protection, 2015). To ensure participants understood that in any research, it is impossible to guarantee complete privacy of data, a two-stage informed consent process was used. Participants were required to answer the following: 1. 'I have read and understood the information provided' 'Yes' or 'No' and 2. 'Please click on the 
following' 'I consent to participate in this research' or 'I do not consent to participate in this research'. Failing to endorse both questions opted participants out of the survey.

\section{Data analysis}

Statistical analysis of the quantitative data was conducted using Statistical Software for the Social Sciences (SPSS, 2014). Bivariate exploratory analyses involved conducting a series of correlations and ANOVAs to examine the relationships between variables and determine variables to be included in the multiple regression analyses. Multiple regression analyses were then used to identify predictors of wellbeing, and to examine the relative importance of possible risk and protective factors. The alpha level in all analyses was set at .05. Strength of the correlation was assessed as: $.2=$ small, $.4=$ moderate, and .6 and above $=$ strong (Field, 2013).

Qualitative data were analysed using a thematic analysis approach (Braun and Clarke, 2006). Two authors (AB and MP) independently coded the free-text comments relating to what maintains wellbeing and then together discussed codes and emerging themes until agreement was reached of the final themes and subthemes.

\section{Results}

\section{Perspectives of workers regarding what it takes to maintain wellbeing}

The free-text qualitative data enabled us to address our first aim and explore the perspectives of workers regarding what it takes for them to maintain wellbeing in their work (possible resources). Of the 41 participants who completed the entire survey, 39 participants (95\%) provided their perspectives regarding what helps to maintain wellbeing in their role. Responses varied in length, ranging from three sentences to multiple paragraphs. Thematic analysis revealed four broad themes and seven subthemes. These are outlined below with quotes to highlight each theme.

\section{Theme 1: Relationships and support seeking.}

One of the most commonly reported facilitators to wellbeing related to relationships, connection and support seeking. There were two subthemes described within this theme:

\section{a) Colleagues, team and peer support.}

Approximately $50 \%$ of participants $(n=20)$ reported that positive relationships and supports within the work environment were crucial to wellbeing. Participants spoke of opportunities for team members to debrief and provide and receive peer support: 
Having a good staff/team environment is probably the most useful however, having teammates who are supportive and willing to debrief and offer emotional support is priceless. (P16)

Support from other colleagues, and attending monthly clinical presentations is very helpful in knowing that other therapists are also working with complex clients, and also receiving support in working with traumatised clients in this way. (P30)

The connection between team members was highlighted as important, in the context of having shared values and ethics, opportunities to connect informally and feel safe amongst colleagues. Humour and rituals to support relationships within the workplace, such as having a cup of tea or share in team-building or workplace wellbeing activities, were also described as useful to maintaining wellbeing:

I find collegial relationships, little rituals, sharing a cup of tea or sending a humorous email, helps me on the stressful days and allows me to be more connected to some of my colleagues (P25)

If the team is well connected, there is a sense of enjoying coming to work and spending time together which can assist when things are difficult (P16)

Trust of managers, having team leaders who advocate for workers' needs and being able to speak freely with managers were also reported to help:

I believe in this work, trust of managers and coordinators are crucial. If lacking and having someone looking over your shoulder, makes you feel you are not in the right place. (P38)

Supportive team leader and colleagues. Team leader to advocate for worker needs on an individual and team basis (P35)

\section{b) Having support (formal and informal) outside of work.}

Participants also reported either seeking out support or appreciating and valuing informal support from family members and friends outside of the workplace as being crucial for their wellbeing: 
I spend time with my family and focus on engaging with my children and making the most of our time together. (P19)

My family has been my main support and coping mechanism, without them or some of my colleagues I don't think I could do this job. (P1)

Formal supports and accessing therapy were also mentioned by participants as being necessary, particularly when they were experiencing challenges in relation to their work:

Currently my mental health has been very impacted by the work context. I am seeking external supports including GP, external supervision and accessing my own mental health care plan. (P26)

\section{Theme 2: Physical and contemplative practices.}

Participants reported on practices that supported wellbeing which were undertaken at a physical, mental or spiritual level. In contrast to the first theme, many of the strategies described in this theme occurred alone or were intrapersonal in nature or in a more private sphere. There were three sub-themes described within 'physical and contemplative practices':

\section{a. Connecting with and exercising values.}

Seven participants described how opportunities to connect or exercise their own values were important to maintaining wellbeing. Values that were seen to be important included: autonomy, flexibility and integrity. Several responses related specifically to connecting with or exercising values related to equity and social justice:

I channel my belief about inequality in society in activism and I engage in some political action, participation in marches and protests. (P19)

I have also channelled energy into social justice causes and advocacy, trying to impact our social consciousness and ensure my experience is a positive one. (P10)

Having a framework, philosophy or understanding as to why suffering and injustice occur and what to do about it really helps with maintaining wellbeing in this space. (P21) 


\section{b. Physical and mental activities and rituals.}

Approximately 40 percent of participants $(n=16)$ mentioned physical or mental activities or practices which they believed supported their wellbeing. Exercise was described by the majority of these participants, along with a range of specific physical activities or rituals, including dancing, stretching, yoga, swimming, snorkelling, walking, cooking and eating well and maintaining a sleep routine. Often these activities were described under the phrase 'selfcare':

[Work location] is incredibly beautiful and this provided a great backdrop for taking care of myself through swimming, snorkelling, walking etc. I would regularly go straight from work to the beach for a snorkel where I could immerse myself in another world. (P11)

Engaging in emotional and physical wellbeing activities regularly outside of work (yoga swimming and dancing) has helped me with my self-care). (P30)

Nine participants also mentioned a range of activities or rituals which could be described as being more contemplative in nature, such as meditation, breathing, mindfulness, being in nature and having time alone:

...self-care strategies (exercise, eating well, meditation, being in nature, reading / watching material of interest that is 'not' always related to refugee and human rights politics. (P9)

Breathing as a preventative medicine. I have quite specific breathing techniques I use several times a day. It is a self-care practice preparing my brain for when the stress comes having a healthy mind to cope better with it rather than get reactional. (P32)

\section{c. Faith, spirituality and prayer.}

Five participants reported that maintaining a connection to religious or spiritual beliefs and rituals, such as prayer, helped to maintain wellbeing:

\footnotetext{
Meditation, prayer, spirituality and contemplative practices are all very important to me. (P22)
} 
The faith of my clients and the theological understanding of mine, has helping to find the points that unite us as human beings instead of looking at the things which separate us... my faith sustains not only my work but my life at every level. (P36)

\section{Theme 3: Professional growth.}

Accessing opportunities for professional growth were considered important for wellbeing by many participants- whether self-driven or in the context of formal arrangements for supervision or training. These were either related to clinical supervision or accessing professional development and learning opportunities.

\section{a) Supervision.}

Participants $(\mathrm{n}=15)$ reported that supervision was important for maintaining their wellbeing. Supervision was referred to as a space to gain knowledge and understanding, as well as feel supported and validated. Supervision was most commonly mentioned as being individual or one-on-one supervision, however, participants also specified valuing peer supervision and supervision that was outside or external to the agency.

Regular external supervisor would greatly help to improve and stabilise my wellbeing. I used to receive external supervisor support... The advice and support I received from her was very useful, affirmative, validating and supportive. It helped me manage client-related stress and my personal wellbeing. I felt valued, encouraged and understood. (P3)

Supervision was another key aspect, and there were many times I questioned if I should be doing this work (and therefore maintaining a detention system I did not agree with), whether I was capable, what my purpose was. Through my monthly phone supervision I was often able to recapture some of the things described above. (P11)

b) Access to professional development and learning.

Seeking out and undertaking learning and professional development activities- both formal and informal opportunities were also reported by participants as being important for their wellbeing. 
In different ways I was always trying to increase my skills and knowledge, through reading, professional training, supervision, and I think this also helped with my wellbeing. (P11)

I do enjoy intellectual environments, and the challenge of learning and growing in a role. Ilike training and that feeling of ever improving as a therapist. (P32)

\section{Theme 4: Balance and boundaries.}

Many participants spoke about the importance of work-life balance, "leaving work at work" (P2), having a life and identity that is separate to work and employing some boundaries regarding clients, work, and thoughts when outside of work.

If I find myself thinking about a client while playing with my kids, I acknowledge that I am doing it, then allocate a moment that is more appropriate time to think that through for the client, close the drawer and be present to my kids. I think of opening and closing drawers as a way of 'compartmentalising'. (P32)

Balance was also achieved for some through working part-time, monitoring caseloads, and working flexible hours:

Clear boundaries and expectations around my capacity and current case load are integral. (P16)

Limited exposure. I intentionally don't work full time in this field, as I think that's a recipe for burnout. (P23)

Importantly, in considering strategies and practices to foster wellbeing across multiple themes, one participant highlighted the need for practices to evolve and be revisited in order for them to stay effective:

I find wellbeing is something that has to be constantly worked on in new and different ways in order to maintain my physical and mental health and prevent burnout. What worked at one stage in my working life has not been enough at another stage. (P22)

\section{Quantitative findings}

Factors associated with wellbeing: Univariate and bivariate explorations 
A large proportion of the sample $(38.8 \%, \mathrm{n}=19)$ reported being involved, outside of their work, in political activism and advocacy regarding refugees and asylum seekers and a further $10.2 \%(n=5)$ reported that they preferred to not disclose whether they were involved in these activities. ANOVA analyses examined the effect of involvement in political activism on wellbeing scores (see Table 2). Of importance, involvement in political activism was not associated with participants' wellbeing scores.

Almost all participants $(n=40)$ reported receiving supervision. Most participants received supervision once a fortnight $(42.5 \%, \mathrm{n}=17)$, followed by monthly or less $(32.5 \%, \mathrm{n}$ $=13)$ or weekly $(25 \%, \mathrm{n}=10)$. According to the Supervisory Working Alliance Inventory, perceived rapport with supervisor $(\mathrm{M}=5.2, \mathrm{SD}=1.77)$ was in the average range and in line with norms provided with the scale (norms: $M=5.4$, range 1-7). However, the level of client focus in superyision $(\mathrm{M}=4.86, \mathrm{SD}=1.48)$ that participants reported was significantly below the norm (norms: $\mathrm{M}=5.9$ ), $\mathrm{p}<.05$.

ANOVA analyses examined the effect of supervision frequency on wellbeing scores (Table 2). Those who received weekly supervision, as opposed to fortnightly, monthly or less, reported significantly lower levels of anxiety. No differences were observed between supervision frequency on other aspects of wellbeing.

[INSERT TABLE 2 HERE]

Regarding supervisory alliance constructs (see Table 3 for correlation analyses), there were small to moderate negative correlations between supervisory rapport and depression, stress and STS, indicating that greater rapport was associated with lower levels of distress on these variables. Similarly, total supervisory alliance was small to moderately, negatively correlated with depression (Table 3).

\section{[INSERT TABLE 3 HERE]}

\section{Unique predictors of wellbeing: multivariate analyses.}

Four simultaneous multiple regression models explored unique predictors of wellbeing variables (depression, anxiety, stress, STS). Regression analyses were not conducted for burnout or compassion satisfaction because no trends were evident in the bivariate analyses. The assumptions of multiple regression (normality, linearity and homoscadesity) were assessed and met. Assessment of multicollinearity revealed no variables with correlation coefficients above .9. Either two or three independent variables were included in each regression model based on Steven's (1996) recommendation of approximately 15 cases per independent variable (Pallant, 2013). Included variables were 
selected based on relationships revealed through initial bivariate analyses. All predictor variables included in the models were related to outcome at the bivariate level. Personal trauma history in model 1 was included due to a trend observed at the bivariate level. Table 4 presents regression models 1-4, the predictor variables entered for each model and the unstandardised and standardised regression coefficients for each predictor.

Model 1 explored unique predictors of depression. With the proposed three predictor variables entered, $\mathrm{R}=.724$, indicating that they accounted for $52.4 \%$ (48.5\% adjusted) of the variance in depressive scores, $\mathrm{F}(3,36)=13.24, \mathrm{p}<.001$. All variables (personal trauma history, supervisory alliance, compassion satisfaction) made unique contributions.

Model 2 explored unique predictors of anxiety among therapists using two proposed predictor variables. With these variables entered, $\mathrm{R}=.539$, which showed that these two variables accounted for $29 \%$ (23.4\% adjusted) of the variance in anxiety scores, $F(2,25)=$ $5.12, \mathrm{p}<.05$. Only time spent working in the trauma field contributed unique variance.

Predictors of stress were examined in model 3 where three predictors were entered and $\mathrm{R}=.636$. Together these variables explained $40.4 \%$ (35.6\% adjusted) of the variance in anxiety scores, $\mathrm{F}(3,37)=8.38, \mathrm{p}<.001$. Compassion satisfaction was the only variable that made a unique contribution.

Finally, model 4 explored two predictors of STS. With these variables included, $\mathrm{R}=$ .439 , showing that these variables accounted for $19.3 \%$ ( $15 \%$ adjusted) of the variance in STS scores, $\mathrm{F}(2,38)=4.53, \mathrm{p}<.05$. Only rapport with supervisor made a unique contribution.

[INSERT TABLE 4 HERE]

\section{Associations with supervisory alliance.}

Because rapport and overall alliance with supervisor were revealed as significant predictors of both depression and STS scores, exploration of what aspects of supervision predicted supervisory alliance was justified. Bivariate analyses explored the impact of demographic and sample characteristics on SWAI scores (see Table 5).

No significant differences in mean scores were observed between groups on SWAI scores. However, previous correlation analysis (Table 3) revealed that rapport, client focus, and overall alliance were all significantly, and moderately to strongly, positively correlated with frequency in which emotional support, professional development and education, and mediation is provided in supervision. 


\section{[INSERT TABLE 5 HERE]}

\section{Unique predictors of supervisory alliance.}

Regression analysis was conducted to explore unique predictors of supervisory alliance (model 5). Table 6 reports the predictor variables entered, and the unstandardised and standardised regression coefficients for each predictor. Three variables were included in the regression equation. With three proposed predictor variables entered, $\mathrm{R}=.825$, indicating that the variables explained $68 \%$ (65.4\% adjusted) of the variance in supervisory working alliance scores, $\mathrm{F}(4,36)=19.11, \mathrm{p}<.001$. Level of emotional support and educational/professional development made unique contributions, with emotional support being the most important predictor of supervisory alliance.

[INSERT TABLE 6 HERE]

\section{Discussion}

This study aimed to explore factors or job resources that can foster mental health and wellbeing among workers who support refugees and asylum seekers in Australia. Our first aim was to consider, broadly, participants' perceptions of what it takes to maintain wellbeing in the context of their jobs. Themes that emerged were centred around relational and supportseeking aspects, physical and contemplative practices, professional growth opportunities and maintaining balance and boundaries. What became apparent from these responses was the diversity of resources (practices and activities) reported by participants that they believed were crucial for them- these were often social in nature, particularly in the work context, valuing team or collegial support and opportunities for debriefing, however, many were also reported as private or out-of-work activities and these varied from contemplative or reflective experiences to distraction. Relational resources such as trust and sense of belonging are factors that have been previously found to buffer against poor psychological health for other occupations exposed to trauma, for example, first responders (Tuckey \& Hayward, 2011).

Our second aim sought to explore factors associated with wellbeing. There was overall convergence between qualitative and quantitative findings, particularly regarding aspects related to clinical supervision. However, there were some conflicting results such as those related to political activism.

Previous qualitative research found that therapists felt their engagement in political activism allowed them to feel more helpful, empowered and positive about their contribution 
to society (Apostolidou, 2016), therefore potentially enhancing their compassion satisfaction and serving a protective function. The quantitative data from this study suggested that although a large proportion of participants engaged in political activism, this was not related to mental health and wellbeing. However, the qualitative data suggested that for some, political activism and advocacy was identified as an activity that helped them connect to and demonstrate values of social justice and equality. Only one participant reported that not engaging in activism helped them maintain wellbeing as a way of separating work and personal life.

Our findings support previous claims from the qualitative literature that supervision is crucial to maintaining wellbeing among therapists who work with refugees and asylum seekers (Apostolidou \& Schweitzer, 2017; Barrington \& Shakespeare-Finch, 2013; Guhan \& Liebling-Kalifani, 2011; Robinson, 2013). We found that supervision frequency (weekly) and supervisory alliance were important factors for wellbeing. Our findings also suggest that the emotional and supportive, as well as educational and professional development aspects of supervision predicted supervisory alliance. Rapport with supervisor and overall supervisory alliance appeared to be important in reducing the risk of developing symptoms of depression and STS.

Rapport and alliance relate to human connectedness, an important factor implicated in depression and posttraumatic stress (Herman, 2015; Van der Kolk, Van der Hart, \& Burbridge, 1995; Williams \& Galliher, 2006). A trusting relationship with a supervisor may reduce negative impacts of the work through various mechanisms. It is possible that connection and alliance with supervisor may serve to counter the impact of exposure to trauma stories, much like how the therapeutic relationship serves an important function in addressing trust and relational issues for clients who have endured interpersonal trauma (Herman, 2015). Emotional containment offered by a trusted other- such as supervisor/colleague/mentor, may also assist the therapist process emotions related to the exposure to client suffering. Social support is also a well-known protective factor that buffers against job stress (Bakker et al., 2005; Tuckey \& Hayward, 2011).

Supervision provides an environment in which to reflect on and process therapeutic work with clients, consider countertransference issues, and potentially explore if personal issues or histories are being triggered by the content of therapy (Follette, Briere, Rozelle, Hopper, \& Rome, 2015). Turkus (2013) argues that self-reflection for trauma therapists is critical and that therapists must work to increase their understanding of countertransference, enactments, and vicarious trauma, as well as understanding the need for increased self-care. 
Common countertransference responses include feelings of powerlessness, hopelessness and helplessness and can result from the interaction between clients' feelings and the therapists' own lives and histories (Turkus, 2013). Self-reflection and reflective practice are essential for attending to and addressing these possible reactions, taking into consideration one's own experiences, and allowing therapists to consider how and when to work in new ways, and make sensitive revisions of current practices.

Given that approximately half the sample reported a personal trauma history and that personal trauma history was a strong predictor of depression among therapists in the sample, this highlights the need to find ways of mitigating potential adverse outcomes among those at greater risk. This provides further support for the importance of resources such as reflective practice, supervision, and attending to the supervisory alliance. Supervisors should encourage reflection on emotions that arise in session and reactions to client stories, and should pay attention to the overall emotional wellbeing of the supervisee, encouraging them to seek out therapy or other external supports, where appropriate.

The findings suggest that supervision, when provided weekly, where a strong alliance exists, and where emotional, supportive, educational and professional development needs are met for supervisees, offers the best conditions to foster wellbeing. These findings may be used to guide supervision practices.

\section{Strengths and limitations}

The main strength of this study is that it is the first to use a mixed-methods approach to comprehensively examine resources such as aspects of supervision, that foster wellbeing among people who support refugees and asylum seekers. Further, this study did this by sampling from multiple organisations across Australia in an attempt to establish a more representative sample, rather than limiting the focus to one service or region.

Limitations include the way in which qualitative information was collected. The freetext comment method certainly allowed us to capture detailed information from some participants and enabled us to identify potentially important resources or protective factors that might not have been captured by quantitative measures alone. However, there was no opportunity to ask participants to expand on or clarify what they had written, potentially limiting the depth of these data. Interview methods would be a more appropriate way to achieve a deep understanding of some of the concepts identified in the free-text comments, however, this was beyond the scope of the present project. Further, this research was conducted at a time where there were significant legal implications if participants disclosed sensitive information regarding working within immigration detention systems and the 
decision to conduct an anonymous online survey was deemed an appropriate way of minimising risk of people not participating due to fear of data being linked back to them. It is also possible that this risk might have contributed to the low response rate (23\%) given that as part of informed consent we reminded participants of the possibility of data being subpoenaed and traced back. While the response rate was low, the sample size was reasonable for the purposes of this analysis and considerably larger than previous studies that have examined this topic. The finding that several participants were reluctant to disclose whether they were involved in any political activism suggests some ambiguity about the confidentiality of participating in the research, potentially highlighting fear of repercussions of being involved in the research.

Finally, while the decision to limit the focus to fewer variables was made to reduce the burden of the survey, including measures of coping and receipt of personal therapy would have enhanced the findings of this study.

\section{Conclusion}

The findings presented here go some way in elucidating what aspects of people's personal and professional lives can assist in keeping workers well in order to continue offering support to clients. Engaging in important social and individual activities and practices which were personal and linked to individuals' preferences and values, and receiving supervision which incorporated both emotional/supportive aspects and professional development/ education, were found to be important for wellbeing in the current study. The benefit of drawing from the JD-R model is that it highlights that the mental health and wellbeing of workers can be fostered even when it is impossible to reduce or remove job demands, as is the case in therapists supporting refugees and asylum seekers.

The findings from this study support the notion that while it is obviously important for professionals to employ healthy lifestyle habits and adaptive coping strategies, this should not discount the responsibilities of the organisation to incorporate policies and practices that are in the interests of promoting staff wellbeing. These findings align with a trauma-informed self-care model, in which maintenance of wellbeing involves a shared responsibility between the worker to engage in individual self-care activities, and the organisation to provide workbased support (Sallouma, Choib, \& Stoverc, 2019).

\section{Acknowledgements}


We would like to acknowledge the following organisations that supported and promoted this research: ASeTTS, STTARS, Foundation House, Companion House, QPASTT, Melaleuca Refugee Centre, STARTTS, and OSSTT.

\section{Conflict of interest}

The authors have no conflict of interest to declare.

\section{Funding}

No funding was received to conduct this research.

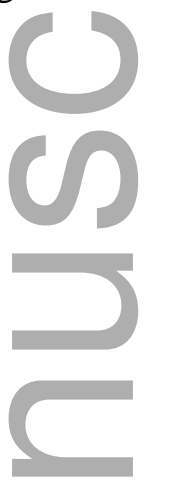

\section{References}

Apostolidou, Z. (2016). Constructions of emotional impact, risk and meaning among practitioners working with asylum seekers and refugees. Counselling and Psychotherapy Research, 16(4), 277-287.

Apostolidou, Z., \& Schweitzer, R. (2017). Practitioners' perspectives on the use of clinical supervision in their therapeutic engagement with asylum seekers and refugee clients. British Journal of Guidance \& Counselling, 45(1), 72-82.

Baglow, L. (2009). Social work supervision and its role in enabling a community visitor program that promotes and protects the rights of children. Australian Social Work, 62(3), 353-368.

Bakker, A.B., Demerouti, E., \& Euwema, M.C. (2005). Job resources buffer the impact of job demands on burnout. Journal of Occupational Health Psychology, 10, 170-180.

Barrington, A. J., \& Shakespeare-Finch, J. (2013). Working with refugee survivors of torture and trauma: An opportunity for vicarious post-traumatic growth. Counselling Psychology Quarterly, 26(1), 89-105.

Bartolomei, J., Baeriswyl-Cottin, R., Framorando, D., Kasina, F., Premand, N., Eytan, A., \& Khazaal, Y. (2016). What are the barriers to access to mental healthcare and the 
primary needs of asylum seekers? A survey of mental health caregivers and primary care workers. BMC psychiatry, 16(1), 336.

Bober, T., \& Regehr, C. (2006). Strategies for reducing secondary or vicarious trauma: Do they work? Brief Treatment and Crisis Intervention, 6(1), 1.

Bride, B. E. (2004). The impact of providing psychosocial services to traumatized populations. Stress, Trauma, and Crisis, 7(1), 29-46.

Brown, T. A., Chorpita, B. F., Korotitsch, W., \& Barlow, D. H. (1997). Psychometric properties of the Depression Anxiety Stress Scales (DASS) in clinical samples. Behaviour research and therapy, 35(1), 79-89.

Colucci, E., Minas, H., Szwarc, J., Guerra, C., \& Paxton, G. (2015). In or out? Barriers and facilitators to refugee-background young people accessing mental health services. Transcultural psychiatry, 52(6), 766-790.

Deighton, R. M., Gurris, N., \& Traue, H. (2007). Factors affecting burnout and compassion fatigue in psychotherapists treating torture survivors: Is the therapist's attitude to working through trauma relevant? Journal of traumatic stress, 20(1), 63-75.

Department of Immigration and Border Protection. (2015). Australian Border Force Act 2015. Australian Government Retrieved from http://www.austlii.edu.au/au/legis/cth/consol_act/abfa2015225/s42.html.

Efstation, J. F., Patton, M. J., \& Kardash, C. M. (1990). Measuring the working alliance in counselor supervision. Journal of Counseling Psychology, 37(3), 322.

Field, A. (2013). Discovering statistics using IBM SPSS statistics: Sage.

Follette, V.M., Briere, J., Rozelle, D., Hopper, J. W., \& Rome, D. I. (2015). Mindfulnessoriented interventions for trauma: Integrating contemplative practices: Guilford Publications.

Guhan, R., \& Liebling-Kalifani, H. (2011). The experiences of staff working with refugees and asylum seekers in the United Kingdom: A grounded theory exploration. Journal of Immigrant \& Refugee Studies, 9(3), 205-228.

Henry, J. D., \& Crawford, J. R. (2005). The short- form version of the Depression Anxiety Stress Scales (DASS- 21): Construct validity and normative data in a large non- clinical sample. British journal of clinical psychology, 44(2), 227-239.

Herman, J. L. (2015). Trauma and recovery: The aftermath of violence--from domestic abuse to political terror: Hachette UK.

Kadushin, A. (1976). Supervision in social work. CA: Columbia Press. 
Kjellenberg, E., Nilsson, F., Daukantaité, D., \& Cardeña, E. (2014). Transformative narratives: The impact of working with war and torture survivors. Psychological Trauma: Theory, Research, Practice, and Policy, 6(2), 120.

Lansen, J. (2001). What does this work do to us? In N. S. Graessner, Gurris, \& C. Pross (Ed.), At the side of torture survivors: Treating a terrible assault on human dignity (pp. 198211). Baltimore: Johns Hopkins University Press.

Lovibond, S., \& Lovibond, P. F. (1995). Manual for the Depression Anxiety Stress Scales (2nd ed. Vol. 18). Sydney: Psychology Foundation of Australia.

Newnham, E.A., Pearman, A., Olinga-Shannon, S., \& Nickerson. (2019). The mental health effects of visa insecurity for refugees and people seeking asylum: a latent class analysis. Int J Public Health, 64: 763. https://doi.org/10.1007/s00038-019-01249-6

Pallant, J. (2013). SPSS survival manual: McGraw-Hill Education (UK).

Patton, M. (1992). The Supervisory Working Alliance Inventory: A Validity Study.

Pearlman, L. A., \& Mac Ian, P. S. (1995). Vicarious traumatization: An empirical study of the effects of trauma work on trauma therapists. Professional psychology: research and practice, 26(6), 558.

Posselt, M., Deans, C., Baker, A., Procter, N. (2019). Clinician wellbeing: The impact of supporting refugee and asylum seeker survivors of torture and trauma in the Australian context. Aust Psychol, 1-12. Https://doi.org/10.1111/ap.12397

Puvimanasinghe, T., Denson, L. A., Augoustinos, M., \& Somasundaram, D. (2015). Vicarious resilience and vicarious traumatisation: Experiences of working with refugees and asylum seekers in South Australia. Transcultural psychiatry, 1363461515577289.

Qualtrics, L. (2014). Online survey software tools and solutions: Qualtrics. In.

Robinson, K. (2013). Supervision found wanting: experiences of health and social workers in non-government organisations working with refugees and asylum seekers. Practice, 25(2), 87-103.

Robinson, K. (2014). Voices from the front line: Social work with refugees and asylum seekers in Australia and the UK. British Journal of Social Work, 44, 1602-1620. doi: 10.1093

Robjant, K., Robbins, I., \& Senior, V. (2009). Psychological distress amongst immigration detainees: A cross- sectional questionnaire study. British journal of clinical psychology, 48(3), 275-286. 
Salloum, A., Choi, M. J., \& Stover, C. S. (2019). Exploratory study on the role of traumainformed self-care on child welfare workers' mental health. Children and Youth Services Review, 101, 299-306.

Sexton, L. (1999). Vicarious traumatisation of counsellors and effects on their workplaces. British Journal of Guidance and Counselling, 27(3), 393-403.

Shulman, L. (1982). Skills of supervision and staff management. SItaska, IL: Peacock.

Silove, D., Steel, Z., \& Watters, C. (2000). Policies of deterrence and the mental health of asylum seekers. Jama, 284(5), 604-611.

SPSS, I. (2014). Statistical package for the social sciences. International Business Machines Corporation SPSS Statistics, Armonk, NY, USA.

Stevens, J. (1996). Applied multivariate statistics for the social sciences (3rd ed.). Mahwah, NJ: Lawrence Erlbaum.

Tuckey, M. R., \& Hayward, R. (2011). Global and occupation- specific emotional resources as buffers against the emotional demands of fire- fighting. Applied Psychology, 60(1), $1-23$.

Turkus, J. A. (2013). The shaping and integration of a trauma therapist. Journal of Trauma \& Dissociation, 14(1), 1-10.

Van der Kolk, B. A., Van der Hart, O., \& Burbridge, J. (1995). Approaches to the treatment of PTSD: Trauma Clinic.

Williams, K. L., \& Galliher, R. V. (2006). Predicting depression and self-esteem from social connectedness, support, and competence. Journal of Social and Clinical Psychology, 25(8), 855-874.

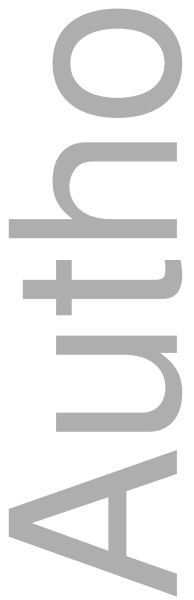


Table 1

Demographics and characteristics

\section{Proportion}

Work status

Full-time

$75.5 \%(\mathrm{n}=37)$

Part-time

$24.5 \%(\mathrm{n}=12)$

\section{Professional background}

Social worker

$46.9 \%(\mathrm{n}=23)$

Psychotherapist

$14.3 \%(\mathrm{n}=7)$

Counsellor

$16.3 \%(\mathrm{n}=8)$

Psychologist

$12.2 \%(\mathrm{n}=6)$

Mental health nurse

$4.1 \%(\mathrm{n}=2)$

Other

$6.1 \%(\mathrm{n}=3)$

\section{Work context}

Within mainland Australia

$83.7 \%(\mathrm{n}=41)$

Regional detention facilities

$4.1 \%(\mathrm{n}=2)$

(Nauru/Manus)

Both regional detention facilities and

$10.2 \%(\mathrm{n}=5)$

within Australia

\section{Client group}

Refugees and asylum seekers in

$73.5 \%(\mathrm{n}=36)$

detention and community

Only with refugees in the community

$12.2 \%(n=6)$

Only with asylum seekers in detention

$14.3 \%(\mathrm{n}=7)$

or community 
Table 2

Differences between groups on wellbeing outcomes: Means and standard deviations from ANOVA analysis

\begin{tabular}{|c|c|c|c|c|c|c|}
\hline \multicolumn{7}{|c|}{ Mean (SD) } \\
\hline & \multicolumn{3}{|l|}{ DASS-21 } & \multicolumn{3}{|l|}{ Pro-QOL } \\
\hline r & Depression & Anxiety & Stress & $\begin{array}{l}\text { Compassion } \\
\text { satisfaction }\end{array}$ & Burn out & $\begin{array}{l}\text { Secondary } \\
\text { traumatic } \\
\text { stress }\end{array}$ \\
\hline Cronbach's alpha coefficient & 0.87 & .83 & .91 & .86 & .80 & .83 \\
\hline \multicolumn{7}{|l|}{ Involved in political activism or } \\
\hline Yes $(n=17)$ & $7.53(7.47)$ & $5.06(6.09)$ & $14.24(9.79)$ & $37.94(4.88)$ & $25.18(5.20)$ & $24.82(6.56)$ \\
\hline No $(n=23)$ & $4.70(5.24)$ & $2.70(3.98)$ & $8.61(7.12)$ & $39.36(5.49)$ & $22.04(5.59)$ & $23.04(4.89)$ \\
\hline \multicolumn{7}{|l|}{ Supervision frequency } \\
\hline Weekly & $4.80(4.13)$ & $1.40(1.90)^{\mathrm{A}}$ & $10.40(9.03)$ & $39.30(6.15)$ & $23.70(7.27)$ & $22.50(5.46)$ \\
\hline $\begin{array}{l}\text { Fortnightly or less (every } 2 \text { to } 3 \\
\text { weeks) }\end{array}$ & $6.59(6.77)$ & $3.88(4.15)^{\mathrm{B}}$ & $11.88(8.20)$ & $38.29(5.12)$ & $23.41(4.85)$ & $23.18(4.69)$ \\
\hline Monthly or less & $5.38(7.54)$ & $3.54(6.33)^{\mathrm{B}}$ & $8.62(9.14)$ & $38.62(5.66)$ & $22.38(6.02)$ & $24.00(7.51)$ \\
\hline
\end{tabular}

Significant values $* \mathrm{p}<.05, * * \mathrm{p}<.001$ indicate a difference between the groups on outcome variable. Where there are more than 2 groups, divergent letters (e.g. A and B) indicate significant differences between groups A and B.

This article is protected by copyright. All rights reserved 
Correlations among variables

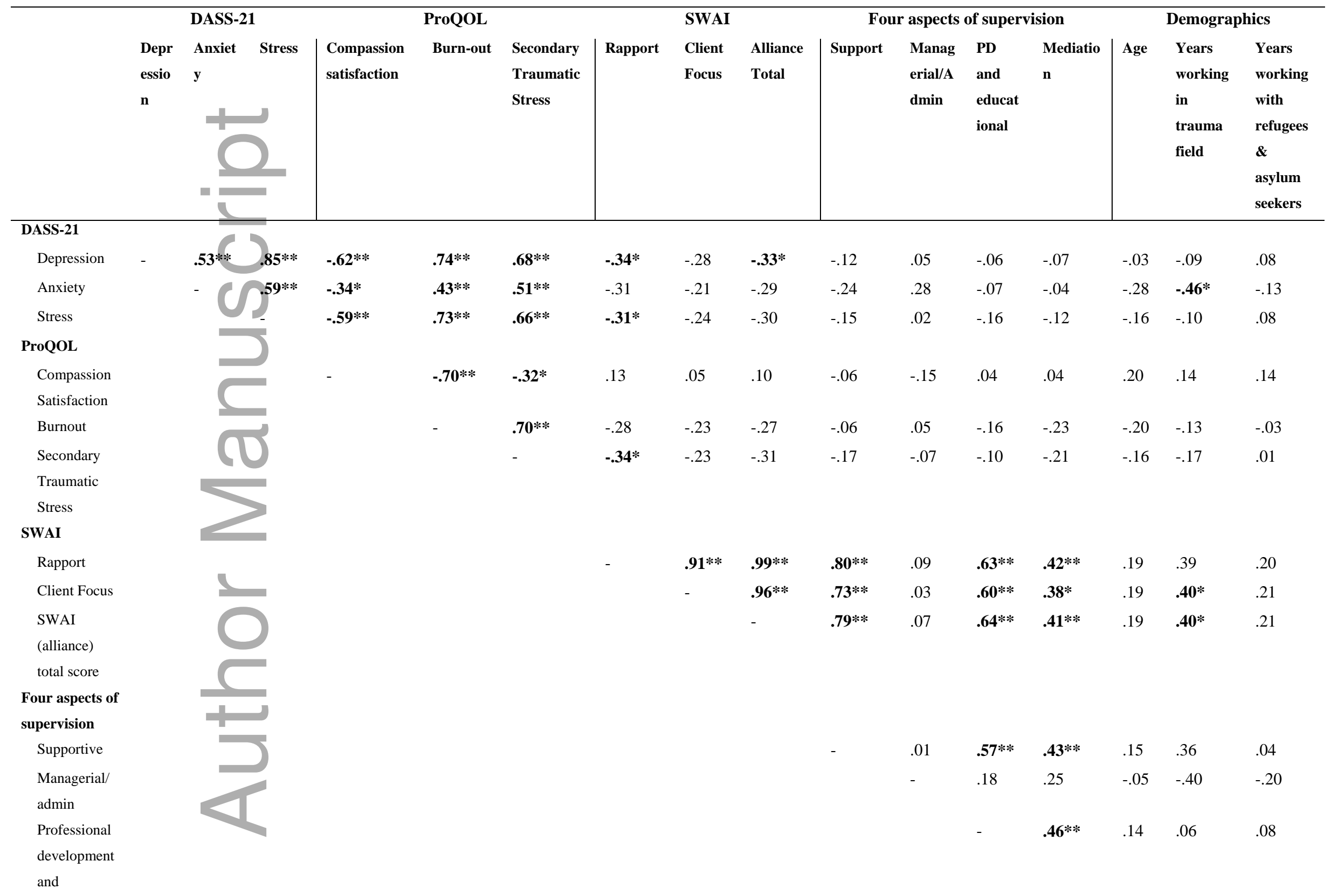

This article is protected by copyright. All rights reserved 
trauma field $* \mathrm{p}<.05, * * \mathrm{p}<.001$. Note. Figures in bold indicate a significant relationship.

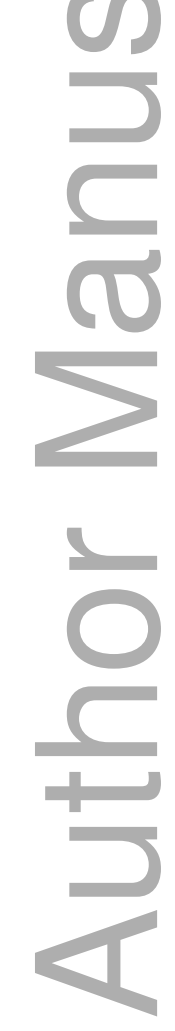

This article is protected by copyright. All rights reserved 
Table 4.

Standardised and unstandardised regression coefficients: Unique predictors of well-being among therapists.

\begin{tabular}{|c|c|c|c|c|}
\hline 2 & Predictor variables & B & Beta & $\mathbf{t}$ \\
\hline Model 1. Predictors of depression & Personal trauma history & -.770 & -.275 & $-2.38^{*}$ \\
\hline $\mathrm{R}=.724$ & Supervisory alliance & -.229 & -.264 & $-2.28 *$ \\
\hline $\mathrm{R}^{2}=.524$ & Compassion satisfaction & -.167 & -.615 & $-5.30 * *$ \\
\hline \multicolumn{5}{|l|}{ Adjusted $\mathrm{R}^{2}=.485$} \\
\hline Model 2. Predictors of anxiety & Time spent working in trauma & -.111 & -.419 & $-2.464 *$ \\
\hline $\mathrm{R}=.539$ & field (years) & & & \\
\hline $\mathrm{R}^{2}=.290$ & Compassion satisfaction & -.074 & -.287 & -1.688 \\
\hline \multicolumn{5}{|l|}{ Adjusted $\mathrm{R}^{2}=.234$} \\
\hline Model 3. Predictors of & Compassion satisfaction & .889 & -.549 & $-4.137 * *$ \\
\hline $\mathrm{R}=.636$ & Rapport with supervisor & -1.343 & -.282 & -1.277 \\
\hline $\mathrm{R}^{2}=.404$ & Level of emotional support in & .321 & .048 & .219 \\
\hline Adjusted $\mathrm{R}^{2}=.356$ & supervision & & & \\
\hline Model 4. Predictors of secondary & Compassion satisfaction & -.307 & -.285 & -1.94 \\
\hline traumatic stress & Rapport with supervisor & -.947 & -.299 & $-2.035^{*}$ \\
\hline $\mathrm{R}=.439$ & & & & \\
\hline $\mathrm{R}^{2}=.193$ & & & & \\
\hline Adjusted $\mathrm{R}^{2}=.150$ & & & & \\
\hline
\end{tabular}

$* \mathrm{p}<.05, * * \mathrm{p}<.01, * * * \mathrm{p}<.001$ 
Table 5

Differences between groups on Supervisory Working Alliance Inventory scores: Means and standard deviations from

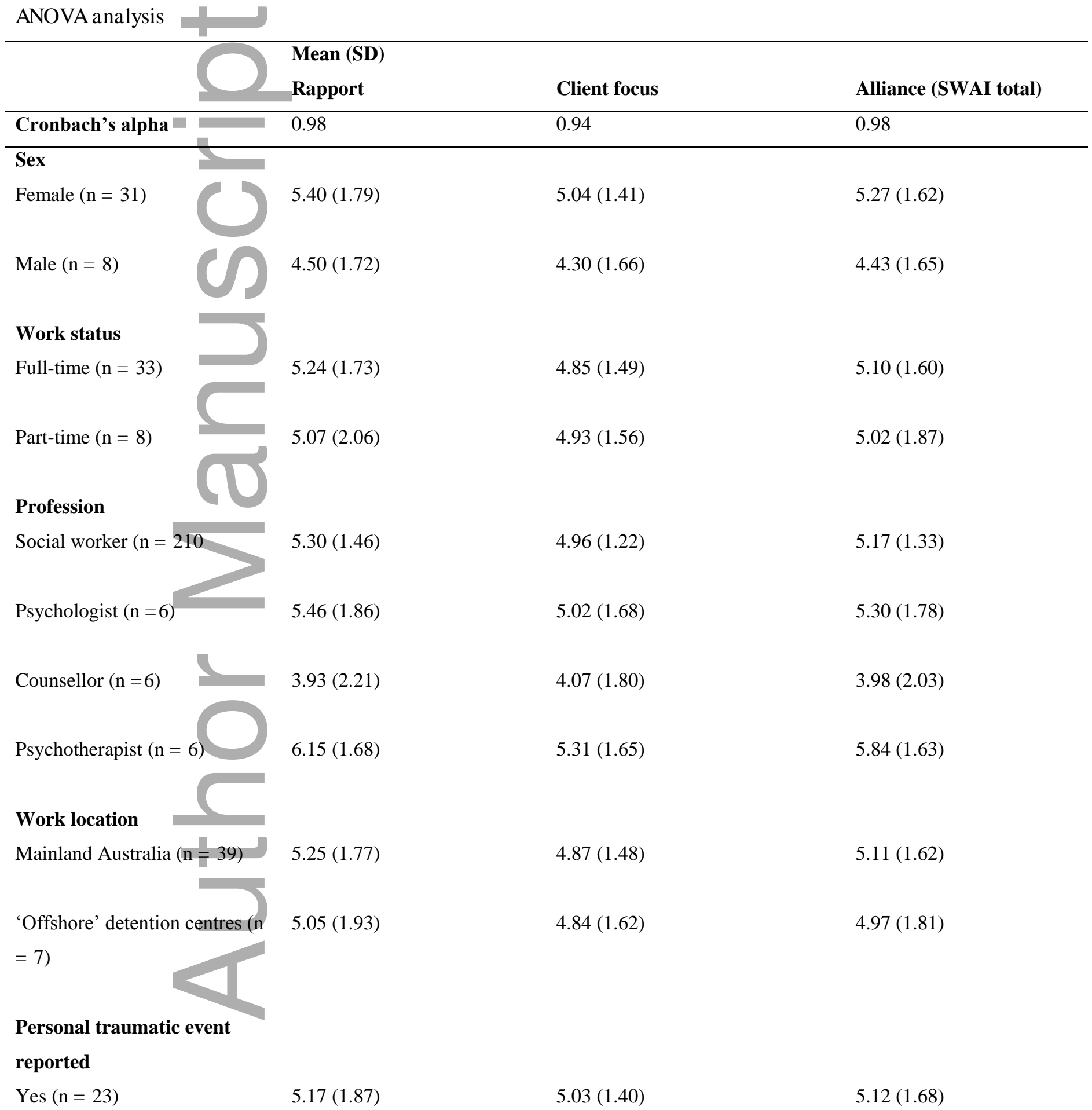




\section{Supervision frequency}

Weekly

Fortnightly or less (every 2 to

$5.98(1.26)$

$5.46(1.20)$

$5.79(1.23)$

3 weeks)

Monthly or less

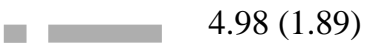

$4.86(1.59)$

$4.93(1.76)$

Significant values $* \mathrm{p}<.05, * * \mathrm{p}<.001$ indicate a difference between the groups on outcome variable. Where there are more than 2 groups, divergent letters (e.g. A and B) indicate significant differences between groups A and B.

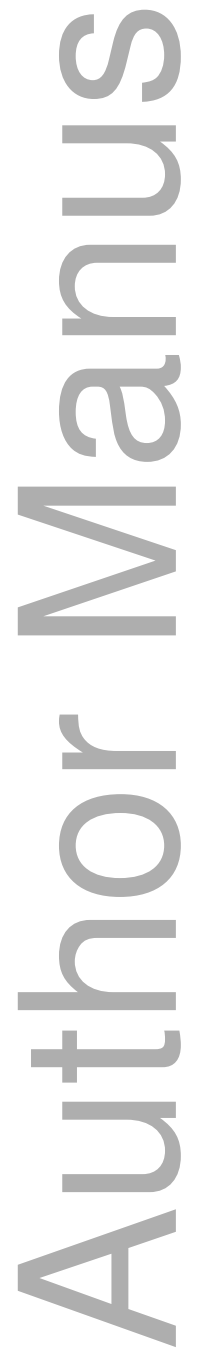


Table 6. Standardised and unstandardised regression coefficients: Unique predictors of supervisory alliance.

\begin{tabular}{lllll}
\hline & Predictor variables & B & Beta & t \\
\hline $\begin{array}{l}\text { Model 5. Predictors of general } \\
\text { alliance with supervisor }\end{array}$ & Level of emotional support in & .819 & .634 & $5.470^{* *}$ \\
$\mathrm{R}=.825$ & supervision & & \\
$\mathrm{R}^{2}=.680$ & $\begin{array}{l}\text { Level of educational and } \\
\text { professional development }\end{array}$ & .455 & .271 & $2.299^{*}$ \\
Adjusted $\mathrm{R}^{2}=.654$ & $\begin{array}{l}\text { received in supervision } \\
\text { Level of mediation received in }\end{array}$ & .019 & .012 & .108 \\
& supervision & & \\
& & & \\
\end{tabular}

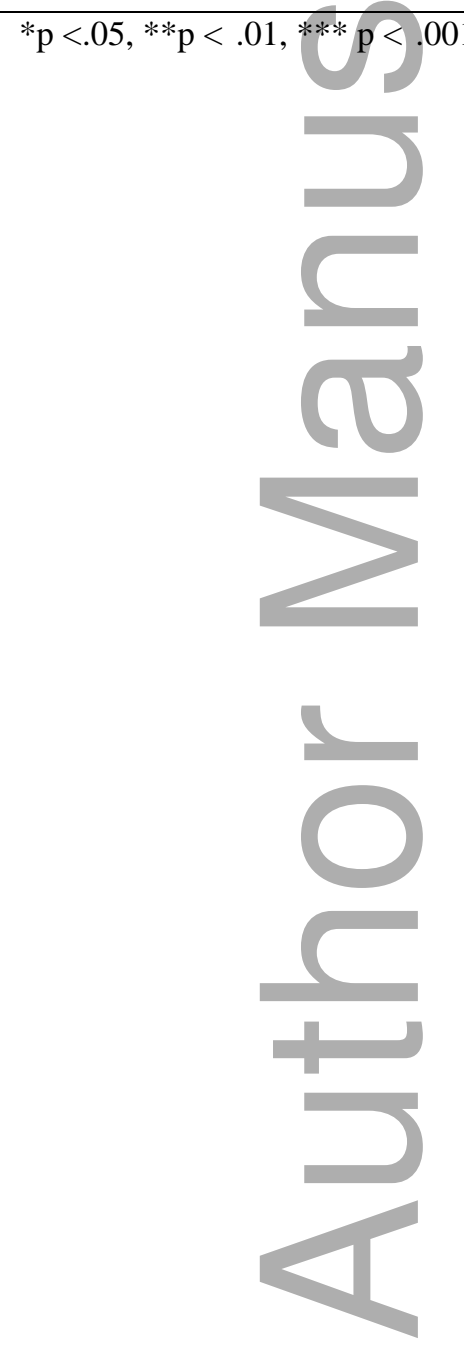




\section{University Library}

\section{- M M I N E R VA A gateway to Melbourne's research publications}

Minerva Access is the Institutional Repository of The University of Melbourne

Author/s:

Posselt, M;Baker, A;Deans, C;Procter, N

Title:

Fostering mental health and well-being among workers who support refugees and asylum seekers in the Australian context

Date:

2020-04-20

Citation:

Posselt, M., Baker, A., Deans, C. \& Procter, N. (2020). Fostering mental health and well-being among workers who support refugees and asylum seekers in the Australian context. HEALTH \& SOCIAL CARE IN THE COMMUNITY, 28 (5), pp.1658-1670. https:// doi.org/10.1111/hsc.12991.

Persistent Link:

http://hdl.handle.net/11343/275666 